\title{
PREVALENCE OF DEPRESSION IN FIRST-YEAR MEDICAL STUDENTS AT AIRLANGGA UNIVERSITY, INDONESIA
}

\author{
Dina Arini Izzah*1, Suksmi Yitnamurti², Nancy Margarita Rehatta ${ }^{3}$
}

${ }^{1}$ Faculty of Medicine, Universitas Airlangga, Indonesia, ${ }^{2}$ Department of Psychiatry, Faculty of Medicine, Universitas Airlangga, Dr Soetomo General Academic Hospital, Indonesia, ${ }^{3}$ Research and Staff Development Unit, Faculty of Medicine, Universitas Airlangga, Dr Soetomo General Academic Hospital, Indonesia

\begin{abstract}
Depression is a mental disorder with a relatively high prevalence rate in medical students around the world. Medical students are often faced with a variety of pressures ranging from academic to social stress so that the prevalence of depression in medical students tends to be higher than general population. Therefore, this study aimed to find out the prevalence of depression in medical students at Airlangga University. This research was a descriptive cross-sectional study. The sample used was 86 firstyear medical students at Airlangga University, Indonesia in the academic year of 2017/2018. The data collection was carried out using Beck Depression Inventory II questionnaires as a measurement instrument. The data was analyzed by descriptive univariate using SPSS 16.0. From 86 samples obtained from firstyear students, $37.20 \%$ of them experienced mental conditions that were considered abnormal (mean score of 10.14 \pm 7.093 ), starting from mild mood disturbance (23.26\%) to the most severe category, severe depression (1.16\%). There was no extreme depression category in this study. Furthermore, mean score of male subjects is $8.57 \pm 6.120$ while mean score of female subjects is $10.64 \pm$ 7.351. This study revealed that the prevalence of depression in first-year medical students at Airlangga University in the second semester of academic year 2017/2018 is quite high, which is more than one third of the total respondents while the prevalence in female subjects is higher than in male subjects.
\end{abstract}

\section{INTRODUCTION}

Depression is a symptom of mental disorder characterized by sadness and loss of interest in activities. ${ }^{1}$ Depression usually decrease the productivity because there is a feeling of loss of energy, difficulty concentrating, feeling guilty and useless. Some even have a desire to harm themselves. ${ }^{2}$ Depression can affect mind, mood, and physical health. Depressed people tend to have a lack of enthusiasm, insomnia, and are unable to enjoy life. ${ }^{3}$

18 | e-ISSN: 2723-035X

Published by BKKM (Biro Koordinasi Kedokteran Masyarakat), Faculty of Medicine, Universitas Airlangga

\section{ARTICLE HISTORY}

Received: March 25, 2021

Revised: June 28, 2021

Accepted: June 29, 2021

Published: June 30, 2021

(Online)

doi:

10.20473/jcmphr.v2i1.26477

\section{KEYWORDS}

Depression; first-year; medical student; beck depression inventory II; mental disorder

\section{CORRESPONDING AUTHOR \\ Dina Arini Izzah $\bowtie$ dinariniza@gmail.com Faculty of Medicine, Universitas Airlangga, Jl. Mayjend Prof. Dr. Moestopo 47, Surabaya, Indonesia}

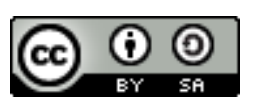


Stress will trigger the amygdala to stimulate the hypothalamus to produce $\mathrm{CRH}$. This hormone triggers the anterior pituitary to secrete ACTH, which causes the adrenal gland to produce cortisol hormone. ${ }^{6}$ Normally, high systemic cortisol levels will give negative feedback to the hippocampus so the hypothalamus stops producing $\mathrm{CRH}^{7}$ However, people who experience depression will have dysfunction in the HPA axis regulation so feedback does not occur.

There are parts of the brain that occur physiologically when they are depressed. Some areas have decreased activity such as anterior cingulate cortex, prefrontral cortex, subgenual cingulate, and ventral striatum but in some other areas increase, such as amygdala and orbitofrontal cortex. Generally the brain structure affected by depression will experience atrophy, however the pituitary will experience the opposite. ${ }^{7}$ This change might affect a person's cognitive condition.

Medical students are often faced with a variety of pressures ranging from academic to adaptation and social stress, so that the prevalence of depression in medical students tends to be higher than that of the general population. ${ }^{8}$ Various studies were conducted to determine the prevalence rate of depression in medical students. The results for each study varied considerably. A study showed that the prevalence rate of depression in first-year medical students was 57\%.9 Another study showed a depression rate of $21.5 \%$ in first-year medical students. ${ }^{10}$

If followed during the study period, the depression character in the first-year can be grouped into 3 clusters. Cluster 1 consisted of $68.5 \%$ medical students who had a stable low depression score. Cluster 2 was medical students with persistent depression during the study period, as much as $19.7 \%$. Cluster 3 was medical students with depression in the first year and improved during the study period, as much as $11.8 \%{ }^{10}$ Persistent depression if unrecognized and uncontrolled will affect academic performance.

At Airlangga University, there are no studies that show the prevalence of depression in first-year medical students. This prevalence rate is important because various previous studies showed varying results. Therefore, this research is expected to be able to determine the prevalence rate of depression in Airlangga University. The results obtained can be used as a basis for taking action so that medical students do not experience persistent depression and gain better academic performance.

\section{MATERIALS AND METHODS}

This was a descriptive study using crosssectional design. This research was carried out to medical students at Airlangga University. Population studied were firstyear students in the second semester of 2017/2018 academic year. Sample studied were students who are willing to fill out the online-distributed questionnaires. The inclusion criteria of this study were first-year students who wanted to fill out the questionnaire that had been given.

Data was obtained with a validated questionnaire in Indonesian, namely Beck Depression Scale II (BDI II). The questionnaire is a depression measuring instrument consisting of 21 items. Subjects chose one of four statements that best suited to their conditions being experienced on each item. Furthermore, the total score was categorized based on the predetermined cut- 
off. BDI II scores ranged from 0 to 63 . Subjects with score of $0-10$ were considered normal. Those with score of $11-16$ indicated mild mood distubance, 17-20 showed borderline clinical depression, 21-30 were moderate depression, 31-40 were severe depression, while the score above 40 indicated extreme depression. The data were analyzed both statistically with SPSS 16.0 and explained descriptively. The statistic are displayed in the form of table and chart.

\section{RESULTS}

The total number of subject who valid in completing the questionnaire were 86 students. The average total sample is 10.14 with a standard deviation of 7.093 and a median of 9.0 (Table 1). Furthermore, the sample was categorized based on the depression score obtained from the questionnaire. Apparently, only $62.79 \%$ subjects were considered normal, while the other $(37.20 \%)$, or more than one third of the samples, were abnormal. The abnormal subjects consisted of five categories, consisting of $23.26 \%$ subjects with mild mood disturbance, $4.65 \%$ subjects with borderline clinical depression, $8.13 \%$ subjects with moderate depression, and $1.16 \%$ subject suffered severe depression with a BDI II score of 33. However, in this study no one suffered from extreme depression. But, there were two of the respondents who had suicidal thoughts.

The number of male and female subjects in this study was quite unbalanced. The ratios of the number of males to that of females was 1:3. Furthermore, in terms of score depression, female subjects appeared to score higher in average than male subjects. The highest score in male subjects was only 22 $(n=1)$, while the scores of 23-33 $(n=5)$ were experienced entirely by female subjects. This means that the category of severe depression is suffered by female subject.

Table 1. Statistical data on prevalence of depression

\begin{tabular}{lcccc}
\hline & N (\%) & Mean \pm SD & Med & Min-max \\
\hline $\begin{array}{l}\text { Total } \\
\text { Considered }\end{array}$ & $54(62.79)$ & $5.87 \pm 3.144$ & 6.0 & $0-10$ \\
$\begin{array}{l}\text { normal } \\
\text { Considered }\end{array}$ & $32(37.20)$ & $17.34 \pm 5.976$ & 15.0 & $11-33$ \\
$\begin{array}{l}\text { not normal } \\
\text { Mild mood } \\
\text { disturbance }\end{array}$ & $20(23.26)$ & $13.5 \pm 1.638$ & 13.0 & $11-16$ \\
$\begin{array}{l}\text { Borderline } \\
\text { clinical } \\
\text { depression }\end{array}$ & $4(4.65)$ & $18.25 \pm 0.500$ & 18.25 & $18-19$ \\
$\begin{array}{l}\text { Moderate } \\
\text { depression }\end{array}$ & $7(8.13)$ & $25.57 \pm 2.507$ & 25.0 & $22-30$ \\
$\begin{array}{l}\text { Severe } \\
\text { depression }\end{array}$ & $1(1.16)$ & $33.00 \pm 0$ & 33.0 & 33 \\
$\begin{array}{l}\text { Extreme } \\
\text { depression }\end{array}$ & - & - & - & - \\
$\begin{array}{l}\text { Male } \\
\text { Female }\end{array}$ & $21(24.4)$ & $8.57 \pm 6.120$ & 7.0 & $0-22$ \\
\hline $\begin{array}{l}\text { Fem } \\
\text { Fem }\end{array}$ & $10.64 \pm 7.351$ & 9.0 & $0-33$ \\
\hline
\end{tabular}

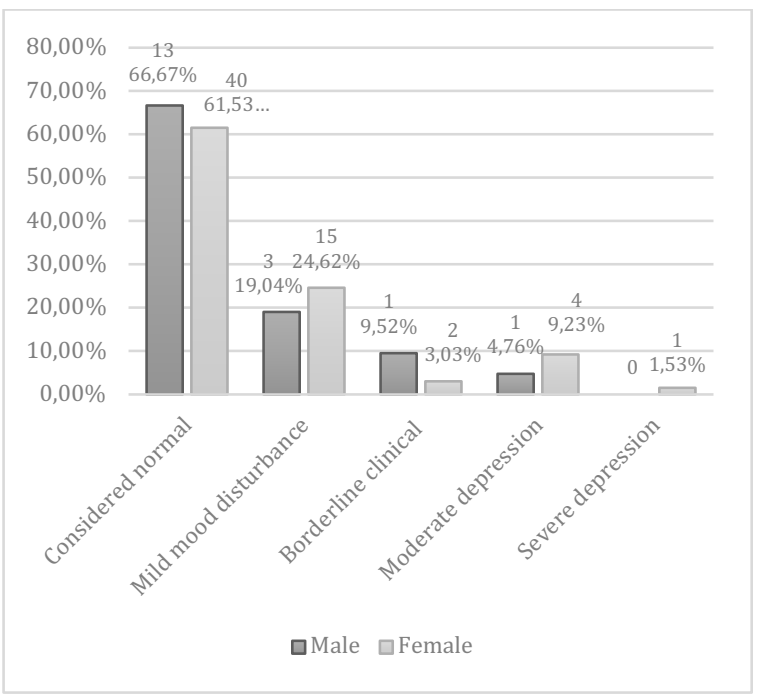

Figure 1. Prevalence of depression chart 


\section{DISCUSSION}

Depression which in this study was measured using Beck Depression Inventory II showed that the number of depressive symptoms in all respondents was $37.20 \%$. A study in India using the Zung's Self Rating Depression Scale (ZSRDS) showed that the prevalence rate of depression in first-year medical students was $9.1 \%$ consisting of mild and moderate depression. ${ }^{11}$ Another study in India using the Beck Depression Scale (BDI) showed a depression rate of $57 \%$, with $33 \%$ classified as mild depression. ${ }^{9}$ Meanwhile, a study in Palestine using BDI II showed that $33.4 \%$ of first-year medical students experienced depression. A total of $9.1 \%$ had severe depression. ${ }^{12}$

According to the previous studies, depression rates in first-year medical students are higher when compared to the year after. This statement is supported by a study in Portugal which showed a depression rate of $72.5 \%$ in the first year, $29.1 \%$ in the second year and $54.9 \%$ in the third year. ${ }^{13}$ Another study compared mean scores of depression using the BDI. The results showed an average score of $8.57,7.13,6.47,6.84$ in the first, second, third and fourth years respectively. ${ }^{10}$

This can be caused by the fact that first-year students still need time to adapt to new environments that are full of pressure. The rate of depression in medical students is higher in the first year of study with the most precipitating factors due to academic stress, followed by social adaptation problems. ${ }^{14}$ Students experience various pressures during lectures, including academic demands, nonacademic activities, time restrictions, and demands for adjustments to the social environment. In medical students, these demands can be even more severe due to various additional challenges, whether the increasingly heavy burden pursued by the target score and time or the challenges of a stressful adaptation to social environment. ${ }^{15}$

Comparison rates of depression in female subjects in this study $(38.47 \%$, mean $10.64 \pm$ $7.351)$ is higher than that in male $(33.33 \%$, mean $8.57 \pm 6.12$ ). Global Burden of Disease showed that the depression rates in the world are always higher in women. In 2017, the prevalence of depression in women were $4.12 \%$ and men were $2.73 \%$. Meanwhile in Indonesia, the prevalence of depression in women were $3.14 \%$ and men were $2.13 \%$. $^{16}$ Likewise in medical students, the depression rate was significantly higher for women $(59.7 \%)$ than men $(45.6 \%) .{ }^{13}$

The previous study stated that this is due to differences in reactivity, one of which is about stress coping styles. ${ }^{17}$ Hormonal change is one of the reasons that can explain the cause of high prevalence of depression in female compared to male. Fluctuating systemic estrogen levels can trigger depression, especially when levels are low in the blood. Whereas in male, even though estrogen levels are low in blood, they do not experience fluctuations. In addition, the brain has an important role in the low prevalence of depression in male so that depression in male is explained more complex. ${ }^{18}$

\section{CONCLUSION}

Prevalence of depression rates in Airlangga University medical students in the first semester of the academic year 2017/2018 is relatively higher than other previous studies. Depression scores in female subjects were found to be higher compared to that in male. 
In fact, the highest score in this study was experienced by a female subject at the level of severe depression.

Due to the high prevalence rate of depression among first-year medical students, it would be very nice if education providers were aware and paid special attention. This is intended to prevent persistent depression that will affect student academic performance.

\section{REFERENCES}

1. National Institute of Mental Health (2017). Depression Overview Risk Factors.

2. World Health Organization (2018). Mental health Depression: let's talk. Available at https://www.who.int/ news/item/30-03-2017-depression-lets-talk-says-who-as-depression-topslist-of-causes-of-ill-health. Accessed June 29, 2018

3. Cui R, Cui R (2015). Editorial: A Systematic Review of Depression. Curr Neuropharmacol, 13(4), 480

4. Sharma B, Wavare R (2013). Academic stress due to depression among medical and para-medical students in Indian Medical College: Health initiatives cross sectional study. J Heal Sci ,3(5), 29-38

5. Thapar A, Collishaw S, Pine D, et al (2012). Effect of stimulus intensity on spine recorded somatosensory evoked potential in dogs. Am J Vet Res, 379(9820), 1056-1067

6. Ionescu DF, Niciu MJ, Mathews DC, et al (2013). Neurobiology of anxious depression: a review. Depress Anxiety, 30(4), 374-85

7. Rot MAH, Mathew SJ, Charney DS (2009). Neurobiological mechanisms in major depressive disorder. Can Med Assoc J, 180(3), 305-313
8. Sidana S, Kishore J, Ghosh V, et al (2012). Magnetic Resonance Imaging in Pregnancies Complicated by Gestational Diabetes Predicts Infant Birthweight Ratio and Neonatal Morbidity. Am J Perinatol, 5(5), 247250.

9. Kumar GS, Jain A, Hegde S (2012). Prevalence of depression and its associated factors using Beck Depression Inventory among students of a medical college in Karnataka. Indian J Psychiatry, 54(3), 223-226.

10. Silva V, Costa P, Pereira I, et al (2017). Depression in medical students: Insights from a longitudinal study. BMC Med Educ, 17(1), 1-9

11. Rajesh L, Reddy EA, Shaik S, et al (2015). Perceived stress and prevalence of depression among firstyear medical students. J Dr NTR Univ Heal Sci, 4(4), 209

12. Shawahna R, Hattab S, Al-Shafei R, et al (2020). Prevalence and factors associated with depressive and anxiety symptoms among Palestinian medical students. BMC Psychiatry, 20(1), 1-13

13. Inam BS (2007). Anxiety and Depression among Students of a Medical College in Saudi Arabia. Int J Health Sci (Qassim), 1(2), 295-300.

14. Basnet B, Jaiswal M, Adhikari B, et al (2012). Depression among undergraduate medical students. Kathmandu Univ Med J, 10(39), 56-59

15. Sreeramareddy CT, Shankar PR, Binu VS, et al (2007). Psychological morbidity, sources of stress and coping strategies among undergraduate medical students of Nepal. BMC Med Educ, 7, 1-8.

16. Global Burden of Disease (2017). Prevalence of depression, males vs. females, Our World in Data. Available at https://ourworldindata.org/grapher/ prevalence-of-depression-males-vsfemales. Accessed July 5, 2018 
17. Abate KH (2013). Gender disparity in prevalence of depression among patient population: a systematic review. Ethiop J Health Sci, 23(3), 283-288
18. Albert PR (2015). Why is depression more prevalent in women? J Psychiatry Neurosci, 40(4), 219-221 